\title{
Effects of combined dietary supplementation with fenofibrate and Schisandrae Fructus pulp on lipid and glucose levels and liver function in normal and hypercholesterolemic mice
}

\author{
This article was published in the following Dove Press journal: \\ Drug Design, Development and Therapy \\ 17 February 2015 \\ Number of times this article has been viewed
}

\author{
Pei-Li Zhu' \\ Si-Yuan Pan' \\ Shu-Feng Zhou ${ }^{2}$ \\ Yi Zhang' \\ Xiao-Yan Wang' \\ Nan Sun' \\ Zhu-Sheng Chu' \\ Zhi-Ling $\mathrm{Yu}^{3}$ \\ Kam-Ming Ko ${ }^{4}$ \\ 'Department of Pharmacology, School \\ of Chinese Materia Medica, Beijing \\ University of Chinese Medicine, \\ Beijing, People's Republic of China; \\ ${ }^{2}$ Department of Pharmaceutical \\ Sciences, College of Pharmacy, \\ University of South Florida, Tampa, \\ FL, USA; ${ }^{3}$ School of Chinese Medicine, \\ Hong Kong Baptist University, \\ Hong Kong, People's Republic of China; \\ ${ }^{4}$ Division of Life Science, Hong Kong \\ University of Science and Technology, \\ Hong Kong, People's Republic of China
}

Correspondence: Si-Yuan Pan Department of Pharmacology, School of Chinese Materia Medica, Beijing University of Chinese Medicine, 6 Wangjing Zhonghuan South Road, Chao Yang District, Beijing I00I02, People's Republic of China

Tel +861084738626

Fax +86 I0 $6472 \quad 1242$

Email siyuan-pan@163.com

Zhi-Ling Yu

School of Chinese Medicine, Hong Kong Baptist University, 7 Baptist University Road, Kowloon Tong, Hong Kong,

People's Republic of China

Tel +85234 I I 2465

Fax+852 34II 246।

Email zlyu@hkbu.edu.hk
Background: Currently, combined therapy using herbs and synthetic drugs has become a feasible therapeutic intervention against some diseases. The purpose of this study was to assess the effects of supplementation with fenofibrate (FF), a chemical drug used for the treatment of hyperlipidemia, and the aqueous extract of Schisandrae Fructus (SF, a Chinese herb) pulp (AqSF-P) or an SF-related synthetic analog, bicyclol (BY), on serum/hepatic lipid levels and liver status in normal and hypercholesterolemic (HCL) mice.

Methods: Male mice obtained from the Institute of Cancer Research (ICR) were fed on a normal diet (ND) or high cholesterol/bile salt $(0.5 \% / 0.15 \%, \mathrm{w} / \mathrm{w}) \operatorname{diet}(\mathrm{HCBD})$ containing FF $(0.03 \%$ or $0.1 \%, \mathrm{w} / \mathrm{w})$ with or without AqSF-P $(0.3 \%-9.0 \%$, based on crude herbal material, $\mathrm{w} / \mathrm{w})$ or BY $(0.025 \%, \mathrm{w} / \mathrm{w})$ for 10 days. Then serum lipid levels and alanine aminotransferase (ALT) activity, as well as hepatic triglyceride (TG), total cholesterol (TC), and glucose levels, were measured.

Results: Oral supplementation with FF significantly reduced serum and hepatic TG, TC, and hepatic glucose levels (approximately 79\%) in mice fed with ND or HCBD. FF supplementation combined with AqSF-P or BY increased FF-induced reduction in hepatic TC and TG contents in ND-fed mice (up to 67\%) and in HCBD-fed mice (up to 54\%), when compared with FF supplementation alone. Hepatic glucose-lowering effect of FF was enhanced (up to $19 \%$ ) by AqSF-P cosupplementation in both normal and HCL mice. FF supplementation enhanced the excretion of fecal TC (by 75\%) in mice fed with HCBD. Fecal TC contents were increased by $14 \% / 9 \%$ in the combination therapy with FF and AqSF-P in ND-/HCBD-fed mice. Serum ALT activity was elevated by $45 \%$ in HCBD-fed mice. FF caused a significant increase in ALT activity by $198 \%$ and $120 \%$ in normal and HCL mice, respectively. BY markedly attenuated the ALT activity by $54 \%$ in mice fed with ND supplemented with $0.1 \% \mathrm{FF}$ and by $42 \%$ in mice fed with HCBD supplemented with $0.03 \%$ FF.

Conclusion: AqSF-P cosupplementation augmented the hepatic lipid-/glucose-lowering effects of FF. BY ameliorated FF-induced liver injury in normal and HCL mice.

Keywords: bicyclol, hepatotoxicity, synergist, fatty liver disease, fat index, interaction

\section{Introduction}

Currently, combination therapy with herbal medicine and chemical drugs has become popular all over the world, ${ }^{1-3}$ especially in the management of noncommunicable diseases, which are the main causes of poor health, disability, and account for nearly two-thirds of deaths worldwide. ${ }^{4}$ It is undisputed that lipid disorders and related disease/complications, such as nonalcoholic fatty liver disease, obesity, metabolic 
syndrome, type 2 diabetes mellitus, heart attacks, and strokes, are among the most predominant challenges to global health. Fenofibrate (FF), a synthetic peroxisome proliferator-activated receptors (PPAR)- $\alpha$ agonist, is well tolerated and mainly used to treat hyperlipidemia in adults who have not responded to nonpharmacological measures in clinical situations. ${ }^{5}$ Clinical studies have shown that FF treatment enhances serum high-density lipoprotein (HDL) levels and reduces triglyceride (TG) and low-density lipoprotein (LDL) levels. ${ }^{6}$ Nevertheless, a high-dose and longterm application of FF has been found to cause liver injury in animals and humans. ${ }^{7-9}$

Schisandrae Fructus (SF, Bei-Wu-Wei-Zi in Chinese) is found in the northwest of People's Republic of China, Korea, and the far east of Russia, and it has a long history of use for various medicinal purposes, such as hepatoprotection, anti-inflammation, antioxidant property, antitumor activity, and resistance to insulin resistance. ${ }^{10-14}$ Our previous studies have demonstrated that SF extracts ${ }^{15-17}$ or its related active compounds and synthetic analogs, such as schisandrin $\mathrm{B},{ }^{18}$ bifendate ${ }^{19}$ and bicyclol, ${ }^{20}$ invariably suppressed hepatic fat accumulation in both normal and hypercholesterolemic (HCL) mice. In the present study, we endeavor to investigate the effects of FF alone and FF in combination with SF on fat/ lipid metabolism, with an objective of establishing a pharmacological basis for its potential application in the treatment of fat/lipid disorders, especially fatty liver disease and obesity, with attention to the potential drug-herb interaction. It has been proposed that the integration of Western and herbal medicines may provide a more effective and safe means of preventing and/or treating fat/lipid disorder, when compared with the use of herbs and drugs alone. Here, an SF-related compound bicyclol (BY), a synthetic dibenzocyclooctadiene derivative (4,4-dimethoxy-5,6,5',6'-dimethylene-dioxy2-hydroxymethyl-2'-carbonyl biphenyl), ${ }^{21}$ was adopted as a positive control for comparison. In the People's Republic of China, BY is clinically prescribed for the treatment of liver injury/viral hepatitis..$^{22,23}$

\section{Materials and methods}

Figure 1 shows the experimental design in the present study.

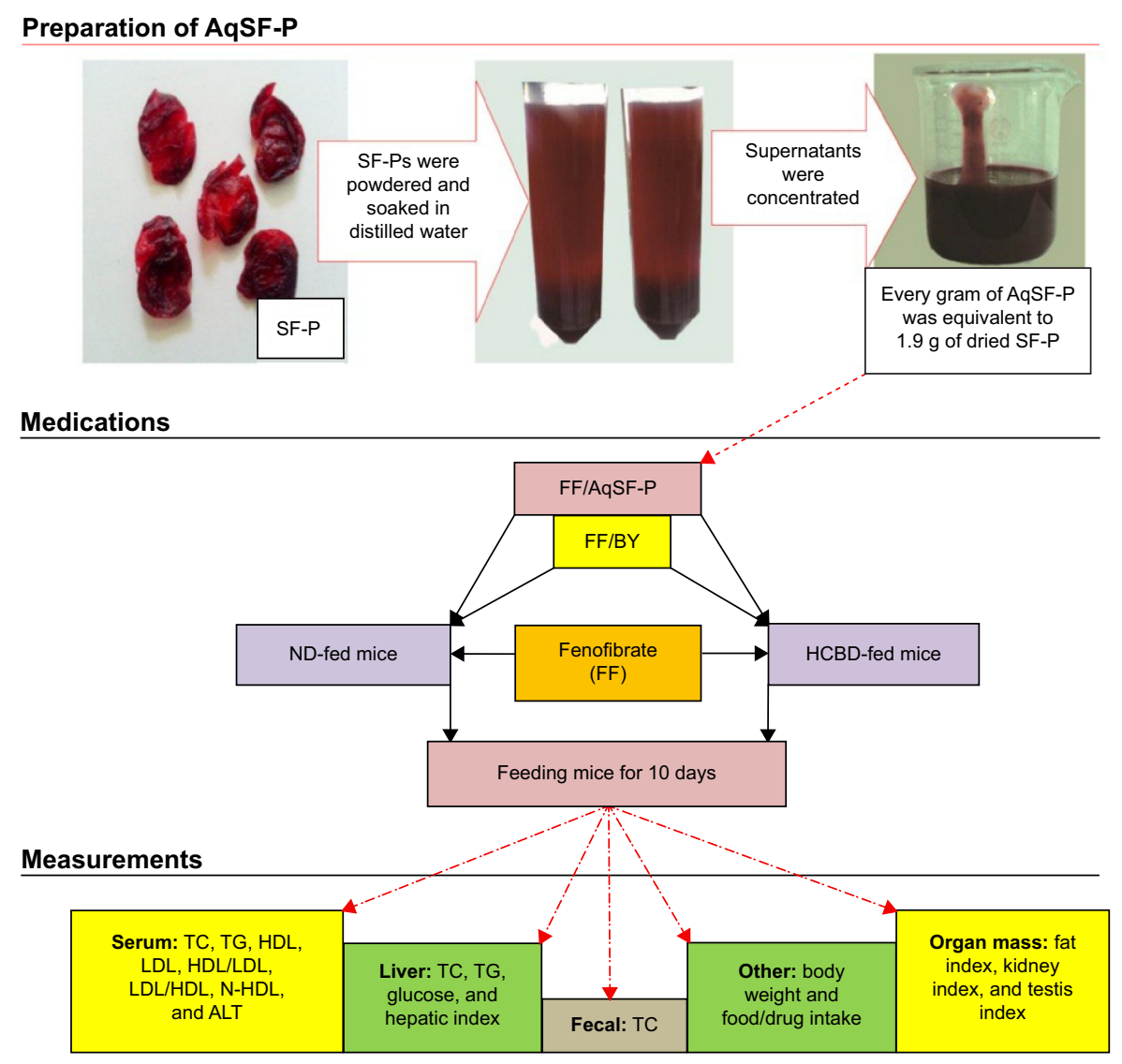

Figure I Experimental design of the study.

Abbreviations: SF-P, Schisandrae Fructus pulp; AqSF-P, aqueous extract of SF-P; BY, bicyclol; TC, total cholesterol; TG, triglyceride; HDL, high-density lipoprotein; LDL, low-density lipoprotein; N-HDL, non-high-density lipoprotein; ALT, alanine aminotransferase; ND, normal diet; HCBD, high cholesterol/bile salt diet. 


\section{Preparation of AqSF-P}

SF, Schisandra chinensis (Turcz.) Baill. (Bei-Wu-Wei-Zi in Chinese), was purchased from the Beijing ShiZhenTang Pharmaceutical Co., Ltd and authenticated by Professor Chun-Sheng Liu in the Beijing University of Chinese Medicine. The SF pulps (SF-P) were manually removed from the seeds; they were then dried and soaked in distilled water for 4 hours at room temperature. After soaking the SF-P with an equal volume (w/v) of distilled water, the pooled aqueous extract was centrifuged at $2,000 \times g$ for 3 minutes. The supernatant was concentrated using a rotary evaporator at $50^{\circ} \mathrm{C}$ to obtain the aqueous extract of SF pulps (AqSF-P), which was stored at $4^{\circ} \mathrm{C}$ until use. Every gram (wet weight) of AqSF-P was equivalent to $1.9 \mathrm{~g}$ of dried SF-P.

\section{Chemicals and reagents}

FF (certificate number 20667) was bought from Beijing Jinxiang Medical Ltd (Beijing, People's Republic of China). BY was obtained from Beijing Union Pharmaceutical Factory (Beijing, People's Republic of China). Cholesterol (certificate number 041103) and bile salt (certificate number 000710) were purchased from Beijing Chemical Reagent Co (Beijing, People's Republic of China). Assay kits for TC (certificate number 131521), TG (certificate number 136281), and glucose (certificate number 133071) were supplied by Zhongsheng Beikong Biotechnology and Science Inc (Beijing, People's Republic of China). Assay kits for HDL, LDL and alanine aminotransferase (ALT) were bought from Zhongsheng Beikong Bio-technology and Science Inc (Beijing, People's Republic of China) or Beijing Leadman Biochemistry Co Ltd (Beijing, People's Republic of China).

\section{Animal treatment}

Male mice obtained from the Institute of Cancer Research (ICR) (grade II, certificate number SCXK [jing] 2012-0001), 18-20 g, were obtained from Vital River Lab Animal Co Ltd (Beijing, People's Republic of China). All animals were housed under a 12-hour-light/12-hour-dark cycle at $20^{\circ} \mathrm{C}-22^{\circ} \mathrm{C}$, with a relative humidity of $50 \%-55 \%$, according to approved standards for laboratory animal care. Water and food were given ad libitum. Blood, liver, and other organ samples were obtained from ether-anesthetized animals that had been fasted for 6 hours (from 6 am to 12 am), and the samples were subjected to biochemical analysis. All experimental procedures were approved by the University Committee on Research Practice at the Beijing University of Chinese Medicine.

\section{Experimental design one: feeding mice with ND supplemented with $0.1 \%$ FF}

This experimental design was aimed at investigating the effects of oral coadministration of FF (a high dose of $0.1 \%$ supplementation, w/w) and AqSF-P on lipid metabolism, hepatic glucose levels, and liver function in normal mice, when compared with FF treatment alone. In this study, 70 mice were randomly assigned to 7 groups of 10 animals in each: group 1, ND; group 2, ND supplemented with $0.1 \%$ FF; group 3, ND supplemented with $0.1 \%$ FF plus $0.025 \%$ BY; and groups $4-7$, ND supplemented with $0.1 \%$ FF plus $0.3 \%, 1.0 \%, 3.0 \%$, and $9.0 \%$ AqSF-P, respectively. Ten days after the treatment, mice were sacrificed and serum/hepatic parameters were determined.

\section{Experimental design two: feeding mice with $\mathrm{HCBD}$ supplemented with $0.03 \% \mathrm{FF}$}

This study aimed to investigate whether dietary supplementation with AqSF-P could produce beneficial effects on FFtreated $(0.03 \%$, w/w) HCBD-fed mice. Mice were divided into six groups of ten animals in each: group 1, ND; group 2, HCBD; group 3, HCBD supplemented with $0.03 \% \mathrm{FF}$; group 4, HCBD supplemented with $0.03 \%$ FF plus $0.025 \%$ BY; and groups 5 and 6: HCBD supplemented with $0.03 \%$ FF plus 3\% and 9\% AqSF-P, respectively. Each medication was administered for 10 days.

\section{Experimental design three: feeding mice with $\mathrm{HCBD}$ supplemented with $0.1 \% \mathrm{FF}$}

In this experimental design, we studied the effects of cosupplementation with AqSF-P and FF $(0.1 \%$, w/w) in HCBD-induced HCL mice. Thus, 70 mice were divided into 7 groups of 10 animals each at random: group 1, ND; group 2, HCBD; group 3, HCBD supplemented with $0.1 \% \mathrm{FF}$; group 4, HCBD supplemented with $0.1 \%$ FF plus $0.025 \%$ BY; and groups 5-7, HCBD supplemented with $0.1 \%$ FF plus $1 \%, 3 \%$, and $9 \%$ AqSF-P, respectively. Mice were fed with HCBD, HCBD supplemented with FF and AqSF-P/BY, or a standard diet for 10 days.

\section{Preparation of serum and hepatic supernatant fractions}

Whole-blood samples obtained from the orbital vein were centrifuged for 8 minutes at $3,000 \times g$ to obtain the serum. Serum samples were stored at $-70^{\circ} \mathrm{C}$ until biochemical analyses within 5 days. Liver tissues were homogenized in nine volumes of $0.9 \%(\mathrm{w} / \mathrm{v}) \mathrm{NaCl}$ solution. The homogenates were centrifuged at $3,500 \times g$ for 15 minutes to obtain the supernatant fraction. 


\section{Biochemical analysis}

Serum and hepatic TG, TC, and glucose levels were manually measured using glycerol phosphate oxidase-paminophenazone (GPO-PAP), cholesterol oxidase phenol 4-aminoantipyrine peroxidase (COD-PAP), and glucose oxidase-peroxidase (GOD-POD) method according to the manufacturer's manual, respectively. In essence, the enzyme-coupled reactions resulted in the formation of quinone imide, which can be measured spectrophotometrically at $500 \mathrm{~nm}$. The concentrations of TG, TC, and glucose in the assay sample were estimated from the equation: (sample OD/standard OD) $\times$ standard concentration, where OD is the optical density. The analytical range of the assay kit is $0-11 \mathrm{mmol} / \mathrm{L}$ for TG, $0-13 \mathrm{mmol} / \mathrm{L}$ for TC, and $0-22 \mathrm{mmol} / \mathrm{L}$ for glucose. An automatic biochemistry analyzer (Synchron CX4PRO; Beckman Coulter, Brea, CA, USA) was used to automatically measure the serum HDL and LDL levels and the ALT activity by a colorimetric method. The intensity of the color formed is proportional to the HDL, LDL, or ALT concentrations in the sample. Serum HDL/LDL, LDL/HDL, and non-HDL (N-HDL) parameters were calculated as the ratio of HDL to LDL, ratio of LDL to HDL, and the TC level minus HDL level, respectively. For the determination of TC contents in feces, mouse feces were collected and dried at room temperature. Dried feces (up to $30 \mathrm{mg}$ ) were extracted with $0.5 \mathrm{~mL}$ chloroformmethanol $(1: 1, \mathrm{v} / \mathrm{v})$ mixture for 12 hours and then centrifuged at $2,000 \times g$ for 5 minutes to obtain the supernatants. Subsequently, an aliquot $(30 \mu \mathrm{L})$ of the fecal supernatants was used to measure the TC levels ( $\mu \mathrm{mol} / \mathrm{g}$ feces) using the abovementioned assay kit.

\section{Measurement of organ indexes}

Mice were sacrificed after blood samples were obtained, and then the body weight and weights of the organs, including liver, epididymal fat, kidney, and testis, were measured. Organ index was estimated from the ratio of the individual organ's weight to the body weight, ie, (organ weight/body weight) $\times 100$. Because hepatomegaly was observed in the mice fed with FF-supplemented diet, fat index, renal index, and testis index were also calculated as follows: (organ weight/body weight - liver weight) $\times 100$.

\section{Statistical analysis}

The data were expressed as means \pm standard errors of the mean and analyzed by one-way analysis of variance. The Dunnett's multiple-comparisons test was used to determine the significance of differences between any two groups using SPSS 17.0. $P<0.05$ was considered significant.

\section{Results \\ Effects of supplementation with FF alone and FF in combination with SF on serum lipids}

Supplementation with FF markedly reduced serum TC (22\%), TG (54\%), and HDL (22\%) levels, as well as the HDL/LDL ratio (23\%) in normal mice. It elevated LDL/ HDL ratio (43\%) in mice fed with ND, while it did not affect the serum LDL and N-HDL levels. Feeding mice with HCBD notably increased serum TC, LDL, and N-HDL levels (up to $48 \%, 390 \%$, and $525 \%$, respectively), as well as the LDL/HDL ratio (up to $392 \%$ ). In contrast, serum TG level and HDL/LDL ratio were decreased by $47 \%$ and $80 \%$, respectively, in HCBD-fed mice, when compared with ND-fed mice. FF supplementation at $0.03 \%$ and $0.1 \%$ concentrations markedly lowered serum TC (38\% and $24 \%$, respectively), LDL (58\% and $39 \%$, respectively), and N-HDL (75\% and 41\%, respectively) levels in HCL mice. However, FF supplementation at $0.03 \%$ decreased HDL level by $22 \%$, when compared with the untreated HCBD-fed mice. Although AqSF-P did not alter the effects of FF on serum TC, TG, HDL, and LDL levels in both ND- and HCBD-fed mice, their combined supplementation increased the HDL/ LDL ratio (by $32 \%$ ) and decreased LDL/HDL ratio (by 33\%) in mice fed with HCBD, when compared with FF treatment alone. Feeding mice with $0.03 \%$ FF/AqSF-P supplemented diet markedly lowered serum TG level up to $31 \%$, when compared with HCBD-fed mice. Combination with FF and BY supplementation reduced serum HDL level (by 21\%) in normal mice, but it increased the HDL level (by 17\%) in HCL mice, when compared with the FF treatment alone. FF/ BY supplement decreased serum HDL levels (by 21\%) in normal mice, but increased serum HDL levels (by 17\%) in HCL mice, compared with FF supplement alone (Table 1).

\section{Effects of supplementation with FF alone and FF in combination with SF on hepatic lipid and glucose levels}

Hepatic TC and TG levels were significantly elevated (up to $141 \%$ and $118 \%$, respectively) in the HCBD-fed mice, when compared with ND-fed mice. FF supplementation markedly reduced the hepatic TC and TG levels in ND-fed mice (up to $64 \%$ and $73 \%$, respectively) and in HCBD-fed mice (up to $59 \%-136 \%$ and $55 \%-82 \%$, respectively). Both AqSF-P and $\mathrm{BY}$ supplementations potentiated the FF-induced reduction in hepatic TC (Figure 2A) and TG (Figure 2B) contents (up to $67 \%$ and $54 \%$, respectively) in ND- and HCBD-fed mice, when compared with FF supplement alone. Dietary 
Table I Effects of dietary supplementation with FF, FF/AqSF-P, and FF/BY on serum lipid profiles in ND- and HCBD-fed mice

\begin{tabular}{|c|c|c|c|c|c|c|c|c|}
\hline Groups & Dose $(\% / w / w)$ & $\begin{array}{l}\text { TC } \\
(\mathrm{mmol} / \mathrm{L})\end{array}$ & $\begin{array}{l}\text { TG } \\
(\mathrm{mmol} / \mathrm{L})\end{array}$ & $\begin{array}{l}\text { HDL } \\
\text { (mmol/L) }\end{array}$ & $\begin{array}{l}\text { LDL } \\
(\mathrm{mmol} / \mathrm{L})\end{array}$ & HDL/LDL & LDL/HDL & $\begin{array}{l}\text { N-HDL } \\
(\mathrm{mmol} / \mathrm{L})\end{array}$ \\
\hline \multicolumn{9}{|l|}{ ND-fed mice } \\
\hline ND & $\mathrm{n} / \mathrm{a}$ & $4.3 I \pm 0.2 I$ & $2.04 \pm 0.18$ & $4.19 \pm 0.21$ & $0.3 I \pm 0.0 I$ & $13.68 \pm 5.37$ & $0.07 \pm 0.00$ & $0.21 \pm 0.09$ \\
\hline $\mathrm{FF}$ & 0.1 & $3.38 \pm 0.23 * *$ & $0.93 \pm 0.07 * *$ & $3.27 \pm 0.19 * *$ & $0.31 \pm 0.02$ & $10.54 \pm 0.37^{* *}$ & $0.10 \pm 0.00 * *$ & $0.31 \pm 0.06$ \\
\hline FF/BY & $0.1 / 0.025$ & $2.76 \pm 0.28 * *$ & $0.78 \pm 0.11 * *$ & $2.58 \pm 0.14^{* *, \dagger}$ & $0.28 \pm 0.02$ & $9.40 \pm 0.5 \mathrm{I} * *$ & $0.11 \pm 0.01 * *$ & $0.4 I \pm 0.27$ \\
\hline \multirow[t]{4}{*}{ FF/AqSF-P } & $0.1 / 0.3$ & $3.17 \pm 0.17 * *$ & $0.88 \pm 0.08 * *$ & $3.06 \pm 0.16 * *$ & $0.30 \pm 0.02$ & $10.42 \pm 0.28 * *$ & $0.10 \pm 0.00 * *$ & $0.23 \pm 0.07$ \\
\hline & $0.1 / 1$ & $3.44 \pm 0.14 * *$ & $0.95 \pm 0.09 * *$ & $3.05 \pm 0.14 * *$ & $0.28 \pm 0.01$ & $11.06 \pm 0.32 *$ & $0.09 \pm 0.00 * *$ & $0.39 \pm 0.04 * *$ \\
\hline & $0.1 / 3$ & $3.24 \pm 0.26 * *$ & $0.8 \mathrm{I} \pm 0.08 * *$ & $2.93 \pm 0.23 * *$ & $0.30 \pm 0.02$ & $9.90 \pm 0.56 * *$ & $0.10 \pm 0.01 * *$ & $0.32 \pm 0.07$ \\
\hline & $0.1 / 9$ & $3.35 \pm 0.26 *$ & $0.73 \pm 0.09 * *$ & $3.19 \pm 0.24 * *$ & $0.30 \pm 0.03$ & $10.75 \pm 0.60 * *$ & $0.10 \pm 0.01 * *$ & $0.60 \pm 0.25$ \\
\hline \multicolumn{9}{|c|}{ HCBD-fed mice } \\
\hline ND & $\mathrm{n} / \mathrm{a}$ & $4.30 \pm 0.27$ & $2.33 \pm 0.11$ & $4.25 \pm 0.22$ & $0.52 \pm 0.05$ & $8.58 \pm 0.47$ & $0.12 \pm 0.01$ & $0.32 \pm 0.08$ \\
\hline HCBD & $\mathrm{n} / \mathrm{a}$ & $6.38 \pm 0.25 * *$ & $1.24 \pm 0.11 * *$ & $4.37 \pm 0.14$ & $2.55 \pm 0.09 * *$ & $1.72 \pm 0.05 * *$ & $0.59 \pm 0.02 * *$ & $2.00 \pm 0.20 * *$ \\
\hline $\mathrm{FF}$ & 0.03 & $3.94 \pm 0.25 \ldots$ & $0.98 \pm 0.08$ & $3.43 \pm 0.23^{\#}$ & $1.07 \pm 0.1 \mathrm{I}^{\#}$ & $3.33 \pm 0.17^{\# \#}$ & $0.31 \pm 0.02^{\#}$ & $0.5 \mathrm{I} \pm 0.1 \mathrm{I}^{\#}$ \\
\hline $\mathrm{FF} / \mathrm{BY}$ & $0.03 / 0.025$ & $4.61 \pm 0.18^{\#, \dagger}$ & $0.93 \pm 0.05^{\#}$ & $4.02 \pm 0.15^{\dagger}$ & $1.13 \pm 0.09 \#$ & $3.7 \mathrm{I} \pm 0.23^{\# \#}$ & $0.28 \pm 0.02^{\# \#}$ & $0.59 \pm 0.1 \mathrm{I}^{\# \#}$ \\
\hline \multirow[t]{2}{*}{ FF/AqSF-P } & $0.03 / 3$ & $4.28 \pm 0.20^{\# \#}$ & $0.86 \pm 0.06 \ldots$ & $3.74 \pm 0.22^{\#}$ & $0.99 \pm 0.06 \#$ & $3.83 \pm 0.24^{\#}$ & $0.27 \pm 0.02^{\#}$ & $0.53 \pm 0.08^{\# \#}$ \\
\hline & $0.03 / 9$ & $3.87 \pm 0.13^{\# \#}$ & $0.85 \pm 0.05^{\# \#}$ & $3.45 \pm 0.13^{\# \#}$ & $0.90 \pm 0.06^{\#}$ & $3.97 \pm 0.25^{\#}$ & $0.26 \pm 0.0 \mathrm{I}^{\#, \dagger}$ & $0.58 \pm 0.05^{\# \#}$ \\
\hline \multicolumn{9}{|c|}{ HCBD-fed mice } \\
\hline ND & $\mathrm{n} / \mathrm{a}$ & $4.29 \pm 0.12$ & $2.18 \pm 0.10$ & $3.80 \pm 0.10$ & $0.46 \pm 0.04$ & $8.7 I \pm 0.53$ & $0.12 \pm 0.01$ & $0.55 \pm 0.04$ \\
\hline HCBD & $\mathrm{n} / \mathrm{a}$ & $5.28 \pm 0.28 * *$ & $1.22 \pm 0.08 * *$ & $3.60 \pm 0.18$ & $1.35 \pm 0.16 * *$ & $3.5 \mathrm{I} \pm 0.96 * *$ & $0.38 \pm 0.04 * *$ & $1.68 \pm 0.14 * *$ \\
\hline $\mathrm{FF}$ & 0.1 & $3.99 \pm 0.19 \ldots$ & $1.12 \pm 0.06$ & $3.16 \pm 0.16$ & $0.82 \pm 0.10^{\#}$ & $4.25 \pm 0.48$ & $0.27 \pm 0.04$ & $0.99 \pm 0.12^{\# \#}$ \\
\hline FF/BY & $0.1 / 0.025$ & $3.84 \pm 0.25 \ldots$ & $1.04 \pm 0.08$ & $3.04 \pm 0.21$ & $0.63 \pm 0.08$ & $5.21 \pm 0.45$ & $0.21 \pm 0.02^{\#}$ & $0.80 \pm 0.05^{\#}$ \\
\hline \multirow[t]{3}{*}{ FF/AqSF-P } & $0.1 / 1$ & $3.89 \pm 0.27^{\#}$ & $1.08 \pm 0.08$ & $3.07 \pm 0.24$ & $0.57 \pm 0.07^{\# \#}$ & $5.61 \pm 0.30^{\dagger}$ & $0.18 \pm 0.0 \mathrm{I}^{\#, \dagger}$ & $0.83 \pm 0.14^{\# \#}$ \\
\hline & $0.1 / 3$ & $3.95 \pm 0.15^{\# \#}$ & I. $14 \pm 0.08$ & $2.96 \pm 0.1 I^{\#}$ & $0.87 \pm 0.09^{\#}$ & $3.7 I \pm 0.39$ & $0.30 \pm 0.03$ & $0.99 \pm 0.10^{\ldots}$ \\
\hline & $0.1 / 9$ & $4.18 \pm 0.14^{\# \#}$ & $1.06 \pm 0.08$ & $3.08 \pm 0.18$ & $0.89 \pm 0.10^{\#}$ & $3.99 \pm 0.70$ & $0.29 \pm 0.03$ & $1.10 \pm 0.13^{\# \#}$ \\
\hline
\end{tabular}

Notes: Mice were fed with ND or HCBD to establish a model of hypercholesterolemia. FF or the combination of FF and AqSF-P or BY at the indicated doses were supplemented with either ND or HCBD.The concentrations of AqFS-P were estimated on the basis of crude herbal material. Ten days after dietary supplementation, serum TC, TG, HDL, LDL, and N-HDL levels, as well as HDL/LDL and LDL/HDL ratios, were measured. Values given are the means $\pm S E M$, with $n=10$. $* P<0.05$, $* * P<0.0$ I vs $N D ;{ }^{*} P<0.05$, ${ }^{\#} P<0.0$ I vs $\mathrm{HCBD} ;{ }^{\dagger} \mathrm{P}<0.05$ vs $\mathrm{FF}$ alone. Statistically significant differences were determined using a one-way ANOVA, followed by Dunnett's multiple-comparisons test. Abbreviations: ND, normal diet; HCBD, high cholesterol/bile salt (0.5\%/0.15\%, w/w) diet; FF, fenofibrate; AqSF-P, aqueous extract of Schisandrae Fructus pulp; BY, bicyclol; w/w, weight/weight; TC, total cholesterol; TG, triglyceride; HDL, high-density lipoprotein; LDL, low-density lipoprotein; N-HDL, non-high-density lipoprotein; SEM, standard error of mean; vs, versus; ANOVA, analysis of variance; n/a, not applicable.

supplementation with FF obviously decreased hepatic glucose levels (up to 66\%) in both ND- and HCBD-fed mice, wherein the hepatic glucose-lowering effect was enhanced by AqSF-P, when compared with the corresponding control mice. In contrast, BY markedly elevated the hepatic glucose contents by $21 \%$ in mice fed on HCBD supplemented with $0.03 \%$ FF (Figure 2C).

\section{Effects of supplementation with FF alone and $\mathrm{FF}$ in combination with SF on fecal TC excretion}

FF did not increase the fecal TC excretion, but FF/AqSF-P or FF/BY supplementation markedly promoted the excretion (up to $24 \%$ ) in ND-fed mice, when compared with the untreated mice. Feeding mice with HCBD markedly increased fecal TC concentrations (up to 226\%), when compared with ND-fed mice. Furthermore, FF supplementation at $0.1 \%$ significantly increased fecal TC excretion by $75 \%$, when compared with untreated HCBD-fed mice. Although FF supplementation at $0.03 \%$ did not alter the fecal TC content in HCL mice, AqSF-P cosupplementation increased the TC excretion by $15 \%(P<0.05)$, when compared with HCBD-fed mice $(P<0.05)$ (Figure 3$)$.

\section{Effects of supplementation with FF alone and FF in combination with SF on liver size and function}

HCBD-fed mice showed markedly increased hepatic weight and index (up to 23\%). ND and HCBD supplemented with FF increased hepatic mass (approximately $91 \%$ or $96 \%$, respectively), when compared with the corresponding untreated mice. Both AqSF-P and BY did not alter FFinduced hepatomegaly. When compared with normal mice, HCL mice showed a marked elevation in serum ALT activity (45\%). Feeding mice with FF-supplemented diet significantly elevated serum ALT activities (up to 198\% and $120 \%$, respectively) in both ND- and HCBD-fed mice. The elevated serum ALT activity caused by FF was suppressed (up to 54\%) by BY and AqSF-P cosupplementation in both ND- and HCBD-fed mice. However, both BY and AqSF-P 

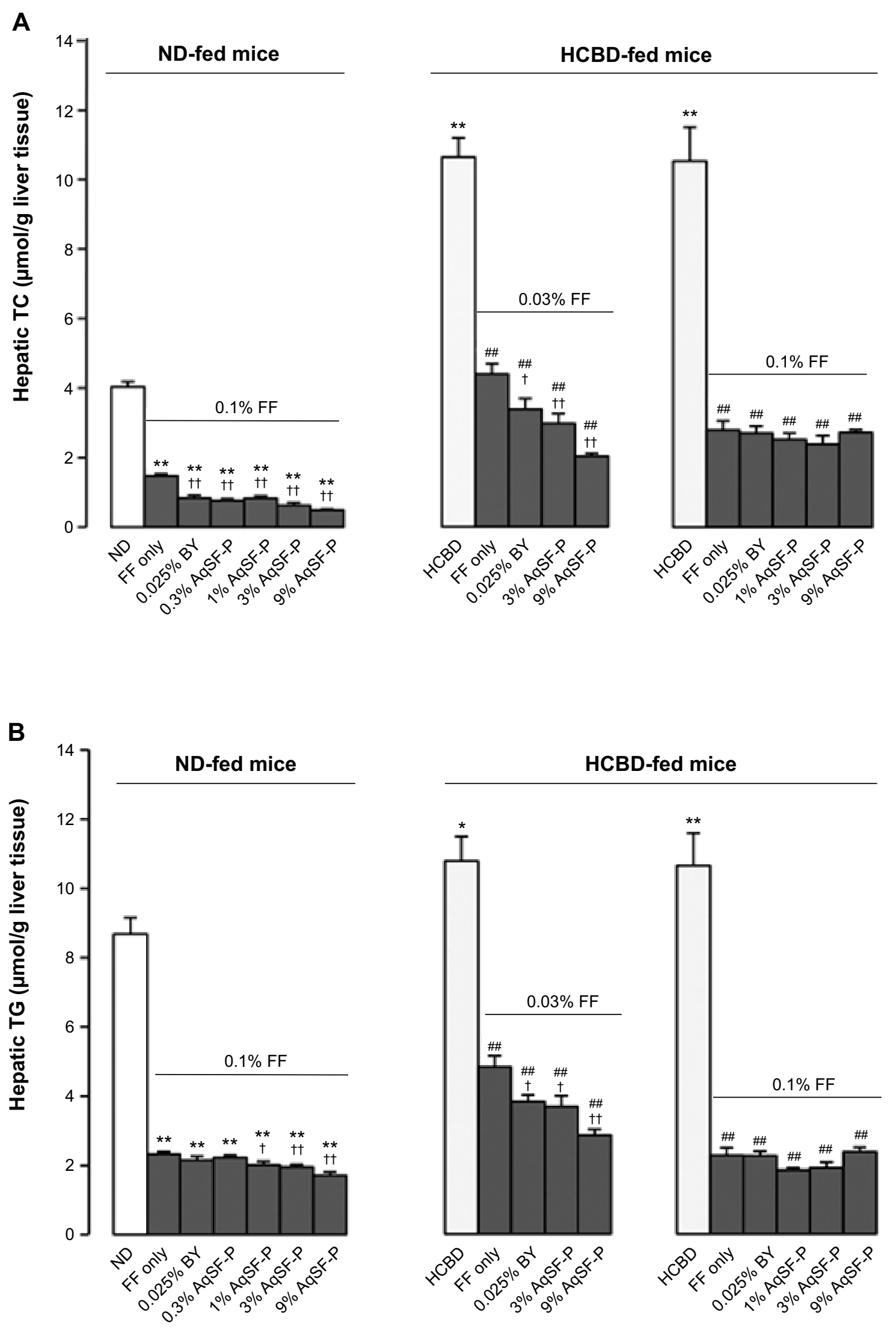

Figure 2 (Continued) 


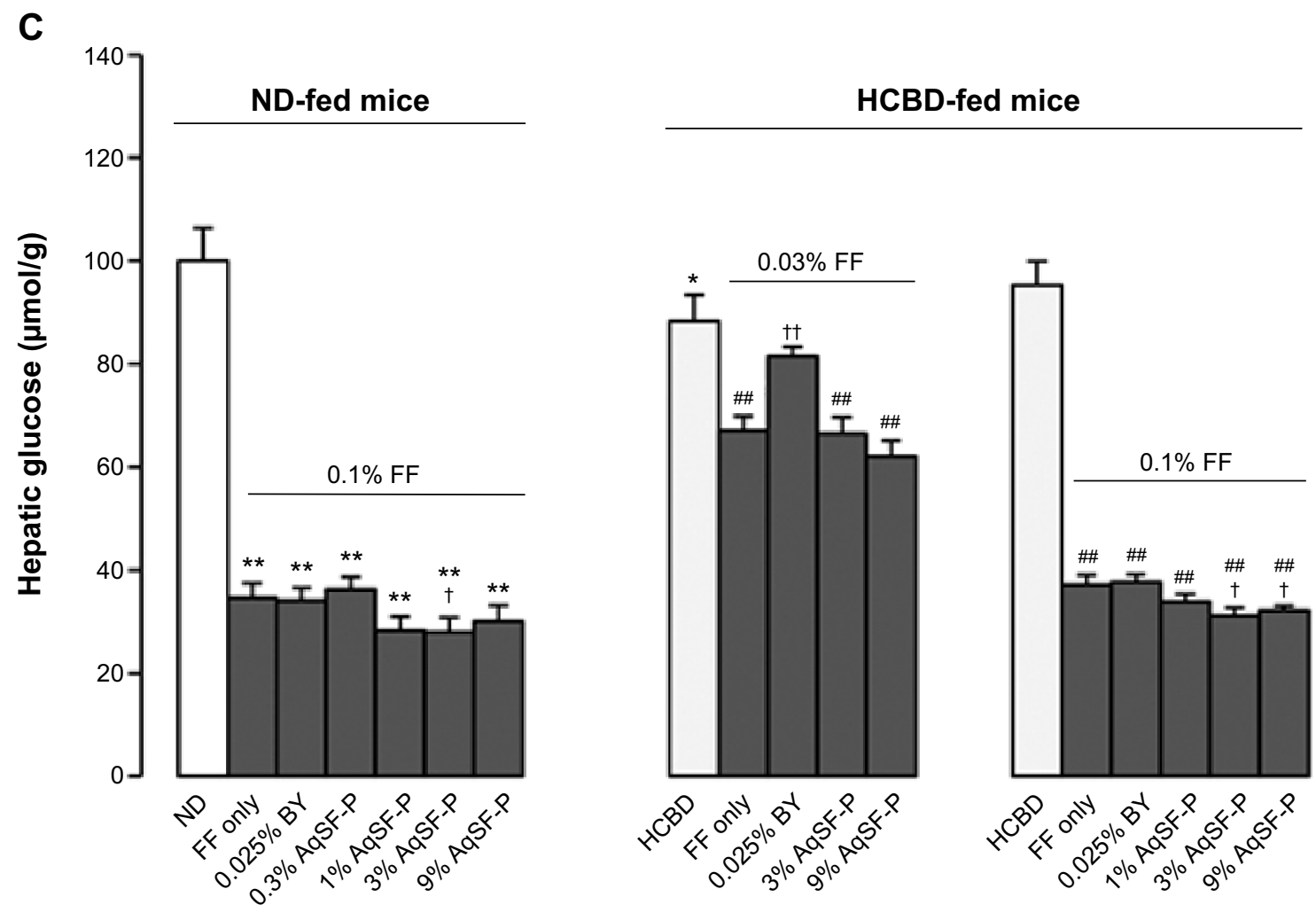

Figure 2 Effects of dietary supplementation with FF, FF/AqSF-P, and FF/BY on hepatic lipid and glucose levels in normal and hypercholesterolemic mice.

Notes: Mice were fed with ND or HCBD without and with supplementation with FF or the combination of FF and AqSF-P or BY at the indicated concentrations. Ten days later, hepatic TC (A), TG (B), and glucose (C) levels were measured. Values given are the means \pm SEM, with $n=10$. $* P<0.05, * * P<0.01$ vs $N D$; $\# P<0.01$ vs $H C B D ;+P<0.05$, ${ }^{H} \mathrm{P}<0.0$ I vs $\mathrm{FF}$ alone. Statistically significant differences were determined using a one-way ANOVA, followed by Dunnett's multiple-comparisons test.

Abbreviations: ND, normal diet; HCBD, high cholesterol/bile salt $(0.5 \% / 0.15 \%$, w/w) diet; FF, fenofibrate; AqSF-P, aqueous extract of Schisandrae Fructus pulp; BY, bicylol; TC, total cholesterol; TG, triglyceride; SEM, standard error of mean; ANOVA, analysis of variance; w/w, weight/weight; vs, versus.
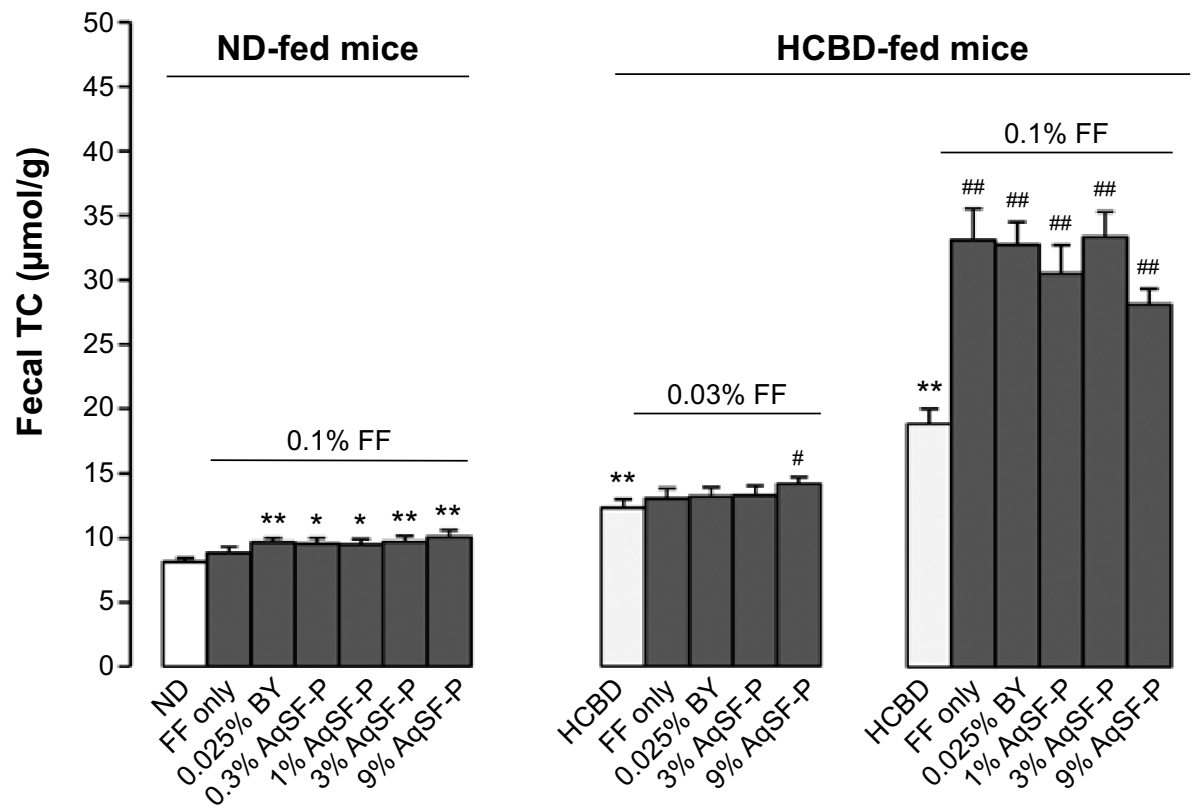

Figure 3 Effects of dietary supplementation with FF, FF/AqSF-P, and FF/BY on fecal cholesterol excretion in normal and hypercholesterolemic mice.

Notes: Mice were fed with ND or HCBD without and with supplementation with FF or the combination of FF and AqSF-P or BY at the indicated concentration. Ten days later, fecal TC content was measured. Values given are the means \pm SEM, with $n=10$. ${ }^{*} P<0.05$, ${ }^{* * P}<0.01$ vs $N D ;{ }^{*} P<0.05$, ${ }^{\# *} P<0.0$ I vs $H C B D$. Statistically significant differences were determined using a one-way ANOVA, followed by Dunnett's multiple-comparisons test.

Abbreviations: ND, normal diet; HCBD, high cholesterol/bile salt (0.5\%/0.15\%, w/w) diet; FF, fenofibrate; AqSF-P, aqueous extract of Schisandrae Fructus pulp; BY, bicyclol; TC, total cholesterol; TG, triglyceride; SEM, standard error of mean; vs, versus; ANOVA, analysis of variance; w/w, weight/weight. 
did not suppress the ALT activity in HCL mice fed with $0.1 \%$ FF supplement (Table 2).

\section{Effects of supplementation with FF alone and FF in combination with SF on fat, kidney, and testis weights}

Supplementation with both $0.03 \%$ and $0.1 \%$ FF significantly decreased the fat index (approximately 54\%) in ND- and HCBD-fed mice, but AqSF-P and BY supplementation did not influence the FF-induced body fat loss. Kidney and testis indexes (as estimated from the equation [organ weight/body weight] $\times 100$ ) were not changed by FF supplementation. However, kidney and testis indexes calculated by an alternative equation ([organ weight/body weight - liver weight] $\times 100$ ) were increased in both normal and HCL mice fed with $0.1 \%$, but not $0.03 \%, \mathrm{FF}$-supplemented diet. It was found that FF supplementation at $0.03 \%$ did not alter the kidney index, but AqSF-P cosupplementation increased the kidney index in HCBD-fed mice (Table 3).

\section{Effects of supplementation with FF alone and FF in combination with SF on body weight and food/drug intake}

There was a progressive increase in body weight of all groups. The weight gains were reduced (approximately 32\%) by FF supplementation at $0.1 \%$, but not at $0.03 \%$, in ND- and HCBD-fed mice. Dietary supplementation in combination with FF and AqSF-P or BY did not change the FF-induced body weight loss. Daily intake of FF was estimated to be $0.06 \mathrm{~g} / \mathrm{kg}$ at $0.03 \%$ supplementation and $0.19 \mathrm{~g} / \mathrm{kg}$ at $0.1 \%$ supplementation. AqSF-P was estimated to be $1.79-2.02 \mathrm{~g} / \mathrm{kg}$ (based on crude herb equivalent) at $1 \%$ supplementation, $5.47-5.85 \mathrm{~g} / \mathrm{kg}$ at $3 \%$ supplementation, and $16.3-17.4 \mathrm{~g} / \mathrm{kg}$ at $9 \%$ supplementation. The daily intake of BY was estimated to be $0.04 \mathrm{~g} / \mathrm{kg}$ (Table 4 ).

\section{Discussion}

Cholesterol in the bloodstream is both synthesized by cells and taken in with food intake. In the present study, cholesterol/

Table 2 Effects of dietary supplementation with FF, FF/AqSF-P, and FF/BY on hepatic weight, hepatic index, and liver function in NDand HCBD-fed mice

\begin{tabular}{|c|c|c|c|c|}
\hline Groups & Dose $(\% / w / w)$ & Hepatic weight (g) & Hepatic index & Serum ALT activity (U/L) \\
\hline \multicolumn{5}{|l|}{ ND-fed mice } \\
\hline ND & $\mathrm{n} / \mathrm{a}$ & $\mathrm{I} .7 \mathrm{I} \pm 0.07$ & $6.01 \pm 0.16$ & $40.80 \pm 7.10$ \\
\hline $\mathrm{FF}$ & 0.1 & $3.00 \pm 0.11 * *$ & $11.46 \pm 0.19 * *$ & $121.70 \pm 14.14^{* *}$ \\
\hline $\mathrm{FF} / \mathrm{BY}$ & $0.1 / 0.025$ & $3.18 \pm 0.07 * *$ & $11.81 \pm 0.17^{* *}$ & $55.60 \pm 5.83^{t \dagger}$ \\
\hline \multirow[t]{4}{*}{ FF/AqSF-P } & $0.1 / 0.3$ & $3.19 \pm 0.07 * *$ & $11.87 \pm 0.17^{* *}$ & $134.60 \pm 13.96 * *$ \\
\hline & $0.1 / 1$ & $3.07 \pm 0.06 * *$ & $11.90 \pm 0.25 * *$ & $149.14 \pm 23.77^{* *}$ \\
\hline & $0.1 / 3$ & $3.00 \pm 0.14 * *$ & $11.40 \pm 0.28 * *$ & $127.30 \pm 12.15^{* *}$ \\
\hline & $0.1 / 9$ & $2.97 \pm 0.08 * *$ & $11.67 \pm 0.23^{* *}$ & $88.30 \pm 5.95 * *$ \\
\hline \multicolumn{5}{|c|}{ HCBD-fed mice } \\
\hline ND & $\mathrm{n} / \mathrm{a}$ & $1.74 \pm 0.13$ & $6.09 \pm 0.40$ & $69.40 \pm 1.28$ \\
\hline HCBD & $\mathrm{n} / \mathrm{a}$ & $2.10 \pm 0.07 *$ & $7.33 \pm 0.11 * *$ & $81.00 \pm 1.05 * *$ \\
\hline $\mathrm{FF}$ & 0.03 & $3.5 \mathrm{I} \pm 0.08^{\#}$ & $\mid \mathrm{I} .6 \mathrm{I} \pm 0.2 \mathrm{I}^{\#}$ & $122.80 \pm 7.28^{\#}$ \\
\hline $\mathrm{FF} / \mathrm{BY}$ & $0.03 / 0.025$ & $3.49 \pm 0.12^{\#}$ & $|I .69 \pm 0.2|^{\# \#}$ & $71.50 \pm 4.5 \mathrm{I}^{+t}$ \\
\hline \multirow[t]{2}{*}{ FF/AqSF-P } & $0.03 / 3$ & $3.25 \pm 0.12^{\#}$ & $11.09 \pm 0.20^{\# \#}$ & $108.70 \pm 8.15^{\# \#}$ \\
\hline & $0.03 / 9$ & $3.52 \pm 0.10^{\#}$ & $11.99 \pm 0.18^{\# \#}$ & $100.00 \pm 4.44^{\#, \dagger}$ \\
\hline \multicolumn{5}{|c|}{ HCBD-fed mice } \\
\hline ND & $\mathrm{n} / \mathrm{a}$ & $1.75 \pm 0.04$ & $6.32 \pm 0.07$ & $60.00 \pm 3.38$ \\
\hline HCBD & $\mathrm{n} / \mathrm{a}$ & $2.07 \pm 0.03 * *$ & $7.38 \pm 0.09 * *$ & $86.90 \pm 7.48 * *$ \\
\hline $\mathrm{FF}$ & 0.1 & $3.69 \pm 0.21^{\# \#}$ & $14.48 \pm 0.48^{\# \#}$ & $191.13 \pm 35.94$ \\
\hline FF/BY & $0.1 / 0.025$ & $3.79 \pm 0.12^{\#}$ & $14.44 \pm 0.24^{\# \#}$ & $150.78 \pm 21.79^{\#}$ \\
\hline \multirow[t]{3}{*}{ FF/AqSF-P } & $0.1 / 1$ & $3.77 \pm 0.06$ & $14.31 \pm 0.18^{\# \#}$ & $296.7 I \pm 63.52^{\ldots \#}$ \\
\hline & $0.1 / 3$ & $4.05 \pm 0.12^{\#}$ & $|4.72 \pm 0.3|^{\# \#}$ & $288.00 \pm 38.37^{\# \#}$ \\
\hline & $0.1 / 9$ & $3.46 \pm 0.12^{\#}$ & $14.10 \pm 0.32^{\# \#}$ & $378.56 \pm 57.42^{\# \#}$ \\
\hline
\end{tabular}

Notes: Mice were fed with ND or HCBD to establish a model of hypercholesterolemia. FF or the combination of FF and AqSF-P or BY at the indicated doses were supplemented with either ND or HCBD. The concentrations of AqFS-P were estimated on the basis of crude herbal material. Ten days after the dietary supplementation, hepatic weight/index and serum ALT activity were measured. Hepatic index was calculated from the following equation: hepatic weight/body weight $\times 100$. Values given are

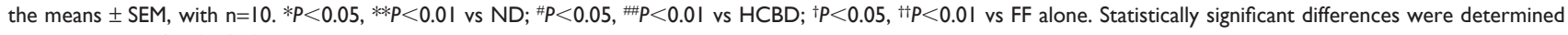
using a one-way ANOVA, followed by Dunnett's multiple-comparisons test.

Abbreviations: ND, normal diet; HCBD, high cholesterol/bile salt (0.5\%/0.15\%, w/w) diet; FF, fenofibrate; AqSF-P, aqueous extract of Schisandrae Fructus pulp; BY, bicyclol; ALT, alanine aminotransferase; SEM, standard error of mean; ANOVA, analysis of variance; vs, versus; w/w, weight/weight; n/a, not applicable. 
Table 3 Effects of dietary supplementation with FF, FF/AqSF-P, and FF/BY on the organ indexes in ND- and HCBD-fed mice

\begin{tabular}{|c|c|c|c|c|c|c|c|}
\hline \multirow[t]{2}{*}{ Groups } & \multirow[t]{2}{*}{ Dose $(\% / w / w)$} & \multicolumn{3}{|c|}{ Organ weight/body weight $\times 100$} & \multicolumn{3}{|c|}{ Organ weight/body weight - liver weight $\times 100$} \\
\hline & & Fat & Kidney & Testis & Fat & Kidney & Testis \\
\hline \multicolumn{8}{|l|}{ ND-fed mice } \\
\hline ND & $\mathrm{n} / \mathrm{a}$ & $1.23 \pm 0.08$ & $1.47 \pm 0.04$ & $0.63 \pm 0.02$ & $1.32 \pm 0.08$ & $1.57 \pm 0.05$ & $0.67 \pm 0.02$ \\
\hline $\mathrm{FF}$ & 0.1 & $0.7 I \pm 0.04 * *$ & $1.57 \pm 0.04$ & $0.68 \pm 0.03$ & $0.80 \pm 0.05 * *$ & $1.77 \pm 0.04 * *$ & $0.76 \pm 0.04 *$ \\
\hline FF/BY & $0.1 / 0.025$ & $0.70 \pm 0.03 * *$ & $1.48 \pm 0.04$ & $0.65 \pm 0.02$ & $0.79 \pm 0.03 * *$ & $1.68 \pm 0.05$ & $0.74 \pm 0.03$ \\
\hline \multirow[t]{4}{*}{ FF/AqSF-P } & $0.1 / 0.3$ & $0.69 \pm 0.04 * *$ & $1.59 \pm 0.04$ & $0.66 \pm 0.03$ & $0.78 \pm 0.05 * *$ & $1.80 \pm 0.05 * *$ & $0.75 \pm 0.03 *$ \\
\hline & $0.1 / 1$ & $0.62 \pm 0.05 * *$ & $1.57 \pm 0.03$ & $0.74 \pm 0.02 * *$ & $0.70 \pm 0.06 * *$ & $1.78 \pm 0.04 * *$ & $0.84 \pm 0.02 * *$ \\
\hline & $0.1 / 3$ & $0.66 \pm 0.05 * *$ & $1.57 \pm 0.04$ & $0.68 \pm 0.03$ & $0.75 \pm 0.06 * *$ & $1.77 \pm 0.05 * *$ & $0.77 \pm 0.03 *$ \\
\hline & $0.1 / 9$ & $0.75 \pm 0.06 * *$ & $1.52 \pm 0.03$ & $0.76 \pm 0.03 * *$ & $0.85 \pm 0.06 * *$ & $1.72 \pm 0.04 *$ & $0.86 \pm 0.03 * *$ \\
\hline \multicolumn{8}{|c|}{ HCBD-fed mice } \\
\hline ND & $n / a$ & I. $17 \pm 0.07$ & $1.49 \pm 0.03$ & $0.47 \pm 0.05$ & $1.25 \pm 0.08$ & $1.59 \pm 0.03$ & $0.50 \pm 0.05$ \\
\hline HCBD & $\mathrm{n} / \mathrm{a}$ & $0.87 \pm 0.05 * *$ & $1.54 \pm 0.03$ & $0.54 \pm 0.03$ & $0.94 \pm 0.06 * *$ & $1.66 \pm 0.03$ & $0.58 \pm 0.03$ \\
\hline $\mathrm{FF}$ & 0.03 & $0.59 \pm 0.03^{\#}$ & $1.47 \pm 0.03$ & $0.47 \pm 0.02$ & $0.67 \pm 0.04^{\# \#}$ & $1.67 \pm 0.04$ & $0.53 \pm 0.02$ \\
\hline FF/BY & $0.03 / 0.025$ & $0.54 \pm 0.02^{\#}$ & $1.5 \mathrm{I} \pm 0.04$ & $0.46 \pm 0.02^{\#}$ & $0.62 \pm 0.02^{\ldots}$ & $I .7 I \pm 0.04$ & $0.52 \pm 0.02$ \\
\hline \multirow[t]{2}{*}{ FF/AqSF-P } & $0.03 / 3$ & $0.61 \pm 0.02^{\#}$ & $1.58 \pm 0.03^{\dagger}$ & $0.48 \pm 0.02$ & $0.69 \pm 0.03^{\#}$ & $1.78 \pm 0.04^{\#, \dagger}$ & $0.54 \pm 0.02$ \\
\hline & $0.03 / 9$ & $0.62 \pm 0.03^{\#}$ & $1.60 \pm 0.05^{\dagger}$ & $0.48 \pm 0.01$ & $0.70 \pm 0.04 \ldots$ & $1.82 \pm 0.06^{\#, \dagger}$ & $0.54 \pm 0.01$ \\
\hline \multicolumn{8}{|c|}{ HCBD-fed mice } \\
\hline ND & $\mathrm{n} / \mathrm{a}$ & $1.03 \pm 0.07$ & $1.63 \pm 0.04$ & $0.6 I \pm 0.02$ & $1.10 \pm 0.07$ & $1.75 \pm 0.05$ & $0.65 \pm 0.02$ \\
\hline HCBD & $\mathrm{n} / \mathrm{a}$ & $0.90 \pm 0.05$ & $1.62 \pm 0.04$ & $0.58 \pm 0.02$ & $0.97 \pm 0.06$ & $1.75 \pm 0.04$ & $0.62 \pm 0.03$ \\
\hline $\mathrm{FF}$ & 0.1 & $0.50 \pm 0.04^{\#}$ & $1.64 \pm 0.07$ & $0.64 \pm 0.03$ & $0.58 \pm 0.05^{\# \#}$ & $1.92 \pm 0.07^{\#}$ & $0.75 \pm 0.03^{\#}$ \\
\hline FF/BY & $0.1 / 0.025$ & $0.53 \pm 0.02^{\#}$ & $1.56 \pm 0.05$ & $0.58 \pm 0.02$ & $0.62 \pm 0.02^{\#}$ & $1.82 \pm 0.06$ & $0.68 \pm 0.03$ \\
\hline \multirow[t]{3}{*}{ FF/AqSF-P } & $0.1 / 1$ & $0.57 \pm 0.03^{\#}$ & $1.70 \pm 0.04$ & $0.65 \pm 0.02$ & $0.67 \pm 0.03^{\#}$ & $1.98 \pm 0.05^{\# \#}$ & $0.75 \pm 0.03^{\# \#}$ \\
\hline & $0.1 / 3$ & $0.57 \pm 0.03^{\#}$ & $1.67 \pm 0.04$ & $0.58 \pm 0.02$ & $0.67 \pm 0.04^{\#}$ & $1.95 \pm 0.05^{\# \#}$ & $0.68 \pm 0.03$ \\
\hline & $0.1 / 9$ & $0.41 \pm 0.03^{\#}$ & $1.57 \pm 0.04$ & $0.6 I \pm 0.04$ & $0.48 \pm 0.03^{\#}$ & $1.83 \pm 0.04$ & $0.7 I \pm 0.05$ \\
\hline
\end{tabular}

Notes: Mice were fed with ND or HCBD to establish a model of hypercholesterolemia. FF or the combination of FF and AqSF-P or BY at the indicated doses were supplemented with either ND or HCBD. The concentrations of AqFS-P were estimated on the basis of crude herbal material. Ten days after the dietary supplementation, organ indexes were estimated. Fatty index was obtained from the epididymal fat pad. Values given are the means $\pm S E M$, with $n=10$. ${ }^{*} P<0.05$, $* * P<0.01$ vs $N D$; ${ }^{*} P<0.05$, $\ldots P<0.01$ vs HCBD; $+P<0.05$ vs FF alone. Statistically significant differences were determined using a one-way ANOVA, followed by Dunnett's multiple-comparisons test. Abbreviations: ND, normal diet; HCBD, high cholesterol/bile salt (0.5\%/0.15\%, w/w) diet; FF, fenofibrate; AqSF-P, aqueous extract of Schisandrae Fructus pulp; BY, bicyclol; SEM, standard error of mean; ANOVA, analysis of variance; w/w, weight/weight; vs, versus; n/a, not applicable.

bile salts-supplemented diet was used to induce HCL in mice. Feeding mice with HCBD for 10 days, serum TC and LDL levels were significantly increased, but serum TG levels were significantly decreased. While serum TC always increased in animal models of HCL, serum TG showed increases, ${ }^{24}$ decreases, ${ }^{17}$ or no changes. ${ }^{25}$ The variable changes of TG may be related to the pattern of food intake and the animal species. Increased level of LDL and decreased level of HDL have been identified as risk factors for cardiovascular diseases, and the correlation is independent of other lipids. ${ }^{26,27} \mathrm{~N}-\mathrm{HDL}$ is the sum of all the cholesterol transported in atherogenic lipoproteins, which has been added as an alternate marker to LDL and is found to be more predictive of cardiovascular risk. ${ }^{28,29}$ In the present study, although LDL and N-HDL levels were markedly elevated, no significant change was observed in HDL level in HCL mice. On the other hand, mice fed with HCBD exhibited an elevation in LDL/HDL ratio, which was found to be positively correlated with the severity of coronary artery stenosis. ${ }^{30}$ In brief, the elevation of serum lipids in HCBD-fed mice indicated that a mouse model of HCL that mimicked the same disorder in humans was successfully developed. ${ }^{31}$
The supplementation with FF reduced serum TC levels in both normal and HCL mice and serum TG levels in normal mice, but not in HCL mice that already showed low levels of serum TG. Because serum LDL and N-HDL levels were markedly elevated, FF significantly reduced LDL and $\mathrm{N}-\mathrm{HDL}$ in HCBD-fed mice, but not in normal mice. In clinical conditions, FF could cause increases or decreases in HDL levels. ${ }^{32-35}$ In the present study, FF supplementation decreased serum HDL levels, which may be related to the drug-induced lowering of serum TC levels. This is because HDL can pick up excessive cholesterol in the blood and take it back to the liver for degradation. As a result, serum HDL levels will be decreased in parallel with the decrease in serum TC levels. The finding thus indicated that the lipid-lowering effect of FF is dependent on the basal blood lipid levels. While AqSF-P did not significantly influence the serum lipid changes caused by FF, it exaggerated the FF-induced decrease in LDL/HDL ratio in HCL mice. In this regard, a high ratio of LDL/HDL is the risk factor for atherosclerosis. ${ }^{36}$

Liver is considered to be the metabolic power station of mammals, where cholesterol homeostasis is regulated by a 
Table 4 Effects of dietary supplementation with FF, FF/AqSF-P, and FF/BY on body weight and food/drug intake in ND- and HCBD-fed mice

\begin{tabular}{|c|c|c|c|c|c|}
\hline Groups & Dose $(\% / w / w)$ & $\begin{array}{l}\text { Body weight (g) } \\
\text { at day } 10\end{array}$ & $\begin{array}{l}\text { Body weight - hepatic } \\
\text { weight }(\mathrm{g}) \text { at day } 10\end{array}$ & Food intake (g/kg/day) & Drug intake (g/kg/day) \\
\hline \multicolumn{6}{|l|}{ ND-fed mice } \\
\hline ND & $\mathrm{n} / \mathrm{a}$ & $28.45 \pm 0.47$ & $26.72 \pm 0.4 I$ & 173.32 & $\mathrm{n} / \mathrm{a}$ \\
\hline $\mathrm{FF}$ & 0.1 & $26.07 \pm 0.64 * *$ & $23.08 \pm 0.53^{* *}$ & 187.42 & 0.19 \\
\hline FF/BY & $0.1 / 0.025$ & $26.85 \pm 0.38 *$ & $23.72 \pm 0.31 * *$ & 189.68 & $0.19 / 0.05$ \\
\hline \multirow[t]{4}{*}{ FF/AqSF-P } & $0.1 / 0.3$ & $26.89 \pm 0.56 *$ & $23.7 I \pm 0.5 I^{* *}$ & 199.44 & $0.20 / 0.60$ \\
\hline & $0.1 / 1$ & $25.87 \pm 0.6 I^{* *}$ & $22.81 \pm 0.57 * *$ & 201.74 & $0.20 / 2.02$ \\
\hline & $0.1 / 3$ & $26.20 \pm 0.72 *$ & $23.20 \pm 0.6 I^{* *}$ & 182.33 & $0.18 / 5.47$ \\
\hline & $0.1 / 9$ & $25.45 \pm 0.54 * *$ & $22.48 \pm 0.48 * *$ & 193.01 & $0.19 / 17.37$ \\
\hline \multicolumn{6}{|c|}{ HCBD-fed mice } \\
\hline ND & $\mathrm{n} / \mathrm{a}$ & $28.46 \pm 0.67$ & $26.72 \pm 0.60$ & 195.36 & $\mathrm{n} / \mathrm{a}$ \\
\hline $\mathrm{HCBD}$ & $\mathrm{n} / \mathrm{a}$ & $28.62 \pm 0.81$ & $26.53 \pm 0.76$ & 184.49 & $\mathrm{n} / \mathrm{a}$ \\
\hline $\mathrm{FF}$ & 0.03 & $30.30 \pm 0.72$ & $26.79 \pm 0.67$ & 183.83 & 0.06 \\
\hline $\mathrm{FF} / \mathrm{BY}$ & $0.03 / 0.025$ & $29.78 \pm 0.53$ & $26.29 \pm 0.42$ & $|78.3|$ & $0.05 / 0.03$ \\
\hline \multirow[t]{2}{*}{ FF/AqSF-P } & $0.03 / 3$ & $29.24 \pm 0.70$ & $26.00 \pm 0.59$ & 180.92 & $0.06 / 5.47$ \\
\hline & $0.03 / 9$ & $29.32 \pm 0.52$ & $25.80 \pm 0.42$ & 193.72 & $0.06 / 17.39$ \\
\hline \multicolumn{6}{|c|}{ HCBD-fed mice } \\
\hline ND & $\mathrm{n} / \mathrm{a}$ & $27.72 \pm 0.49$ & $25.98 \pm 0.46$ & 161.84 & $\mathrm{n} / \mathrm{a}$ \\
\hline HCBD & $\mathrm{n} / \mathrm{a}$ & $28.02 \pm 0.24$ & $25.95 \pm 0.23$ & $|70.9|$ & $\mathrm{n} / \mathrm{a}$ \\
\hline $\mathrm{FF}$ & 0.1 & $25.42 \pm 1.03^{\#}$ & $21.72 \pm 0.85^{\#}$ & 183.91 & 0.18 \\
\hline FF/BY & $0.1 / 0.025$ & $26.26 \pm 0.64^{\#}$ & $22.47 \pm 0.54^{\# \#}$ & 192.09 & $0.19 / 0.05$ \\
\hline \multirow[t]{3}{*}{ FF/AqSF-P } & $0.1 / 1$ & $26.34 \pm 0.43^{\#}$ & $22.58 \pm 0.39 \ldots$ & 179.16 & $0.18 / 1.79$ \\
\hline & $0.1 / 3$ & $27.5 I \pm 0.29$ & $23.46 \pm 0.20^{\#}$ & 195.06 & $0.19 / 5.85$ \\
\hline & $0.1 / 9$ & $24.50 \pm 0.59 \ldots$ & $21.04 \pm 0.52^{\ldots \#}$ & 181.28 & $0.18 / 16.32$ \\
\hline
\end{tabular}

Notes: Mice were fed with ND or HCBD to establish a model of hypercholesterolemia. FF or the combination of FF and AqSF-P or BY at the indicated doses were supplemented with either ND or HCBD. The concentrations of AqFS-P were estimated on the basis of crude herbal material. Ten days after the dietary supplementation, body weight and food $/$ drug intake were estimated. The dosages $(\mathrm{g} / \mathrm{kg} /$ day) based on crude herbal material were determined with the amount of ingested diet $(\mathrm{g} / \mathrm{kg} / \mathrm{day})$ and drug concentration in the diet. Values given are the means \pm SEM, with $n=10$. ${ }^{*} P<0.05,{ }^{*} * P<0.01$ vs $N D$; ${ }^{\#} P<0.05$, ${ }^{\#} P<0.01$ vs HCBD. Statistically significant differences were determined using a one-way ANOVA, followed by Dunnett's multiple-comparisons test.

Abbreviations: ND, normal diet; HCBD, high cholesterol/bile salt (0.5\%/0.15\%, w/w) diet; FF, fenofibrate; AqSF-P, aqueous extract of Schisandrae Fructus pulp; BY, bicyclol; SEM, standard error of mean; ANOVA, analysis of variance; w/w, weight/weight; vs, versus; n/a, not applicable.

complex mechanism. ${ }^{37}$ In the present study, feeding mice with HCBD significantly elevated hepatic TC and TG levels. Dietary supplementation with FF lowered hepatic lipids in both ND- and HCBD-fed mice, as well as promoted fecal TC excretion in HCBD-fed mice, but not in ND-fed mice. Combined dietary supplementation with FF/AqSF-P enhanced the excretion of fecal TC caused by FF alone in both ND- and HCBDfed mice. Our previous studies showed that dietary AqSF-P alone lowered hepatic lipid levels in HCL mice. ${ }^{16}$ Here, FF in combination with AqSF-P further decreased the hepatic lipid content. Studies have also demonstrated that schisandrin B, an active ingredient of SF, decreased fat accumulation in L-02 cells incubated with free acid via the inhibition of adipose differentiation-related protein (ADRP) and sterol regulatory element binding protein-1 (SREBP-1) ${ }^{38}$ which are the principal regulators of steatogenesis and lipolysis. ${ }^{39,40}$

Insulin resistance plays a crucial role in the pathogenesis of nonalcoholic fatty liver disease and type 2 diabetes mellitus. ${ }^{41,42}$ The steatotic liver is also resistant to insulin. ${ }^{43}$ In the present study, FF supplementation notably decreased hepatic glucose contents in both normal and HCL mice, and the effect was augmented by AqSF-P cosupplementation. Studies showed that FF treatment increased the expression of PPAR- $\alpha$ genes and fatty acid $\beta$-oxidation-related genes in visceral adipose tissue. ${ }^{44,45} \mathrm{SF}$ could also improve hepatic insulin sensitivity via the PPAR- $\gamma$ pathways. ${ }^{46}$ All of these actions may contribute to the reduction in hepatic fat/glucose and body weight/fat after dietary intake of FF alone or in combination with AqSF-P, as observed in the present study. Nevertheless, serum glucose levels were not changed by FF, FF/BY, or FF/AqSF-P supplementation (data not shown). Although FF intake increased kidney and testis indexes, their absolute weights were not altered by FF or FF/AqSF-P supplementation (data not shown). However, both fat index and fat weight were decreased. This observation indicated that FF only reduced the body/fat mass but did not influence the growth and development of kidney and testis.

Serum ALT activity is widely adopted as a sensitive marker of tissue damage, particularly liver injury, in both clinical and nonclinical studies. Increased serum ALT activity and hepatomegaly are usually regarded as signs of liver injury. The liver damage in HCL mice is probably related to the accumulation 
of lipids in hepatic tissue, referred to as steatohepatitis, and bile salt-induced oxidative stress. ${ }^{47,48}$ However, elevated ALT activity may result from the increased expression of the ALT gene and/or drug-induced hepatotoxicity in the FF-fed mice. ${ }^{8,49}$ In the present study, the increased ALT activity, but not the hepatic size, caused by FF intake at $0.03 \%$ (approximately $0.06 \mathrm{~g} / \mathrm{kg}$ / day) was suppressed by BY and AqSF-P. The hepatoprotective effect may be related to the hepatic lipid-lowering and anti-inflammatory effects of AqSF-P and BY.50,51 However, AqSF-P and BY did not decrease the ALT activity in mice fed with $0.1 \% \mathrm{FF}$ (up to $0.18 \mathrm{~g} / \mathrm{kg} /$ day). Apparently, there was no hepatoprotection of AqSF-P and BY on liver injury induced by high dose of FF or in the case of severe liver damage. Although $\mathrm{SF}$ and its related active components exhibited hepatoprotective effect, our previous study showed that schisandrin B at high doses could increase serum ALT activity and liver mass. ${ }^{52}$
In conclusion, supplementation with a combination of FF (a lipid-lowering agent) and an aqueous extract of SF pulp (AqSF-P), derived from a commonly used Chinese herb, enhanced the hepatic fat- and glucose-lowering effect of FF, as well as increasing TC excretion in stools in both normal and HCBD-induced HCL mice. BY, an SF-related synthetic analog, also potentiated the effects of FF-induced reduction in hepatic TC and TG levels. However, AqSF-P and BY did not alter the effects of FF on serum lipids in ND- and/or HCBD-fed mice. Combined supplementation with FF and AqSF-P reduced the LDL/HDL ratio, which is a risk factor for atherosclerosis. AqSF-P and BY protected against liver injury caused by FF intake at the dose of $0.03 \%(0.06 \mathrm{~g} / \mathrm{kg} /$ day), but not at $0.1 \%(0.18 \mathrm{~g} / \mathrm{kg} /$ day $)$ in HCL mice (Table 5$)$. The ensemble of results obtained from the present study indicates that AqSF-P can augment the FF-induced reduction of

Table 5 A summary of the present study

\begin{tabular}{|c|c|c|c|c|c|}
\hline & \multirow[t]{2}{*}{ HCBD (vs ND) } & \multicolumn{2}{|c|}{$\begin{array}{l}\text { Dietary FF } \\
\text { (vs ND or HCBD) }\end{array}$} & \multirow[t]{2}{*}{$\begin{array}{l}\text { Dietary FF/AqSF-P } \\
\text { (vs FF alone) }\end{array}$} & \multirow[t]{2}{*}{$\begin{array}{l}\text { Dietary FF/BY } \\
\text { (vs FF alone) }\end{array}$} \\
\hline & & $0.03 \%$ & $0.1 \%$ & & \\
\hline \multicolumn{6}{|l|}{ ND-fed mice } \\
\hline Serum TC & $\mathrm{n} / \mathrm{a}$ & $\mathrm{n} / \mathrm{a}$ & $\downarrow$ & - & - \\
\hline Serum TG & $\mathrm{n} / \mathrm{a}$ & $\mathrm{n} / \mathrm{a}$ & $\downarrow$ & - & - \\
\hline Serum HDL & $\mathrm{n} / \mathrm{a}$ & $\mathrm{n} / \mathrm{a}$ & $\downarrow$ & - & $\downarrow$ \\
\hline Serum LDL & $\mathrm{n} / \mathrm{a}$ & $\mathrm{n} / \mathrm{a}$ & - & - & - \\
\hline Serum LDL/HDL & & & $\uparrow$ & - & - \\
\hline Serum ALT & $\mathrm{n} / \mathrm{a}$ & $\mathrm{n} / \mathrm{a}$ & $\uparrow$ & - & $\downarrow$ \\
\hline Hepatic TC & $\mathrm{n} / \mathrm{a}$ & $\mathrm{n} / \mathrm{a}$ & $\downarrow$ & $\downarrow$ & $\downarrow$ \\
\hline Hepatic TG & $\mathrm{n} / \mathrm{a}$ & $\mathrm{n} / \mathrm{a}$ & $\downarrow$ & $\downarrow$ & - \\
\hline Hepatic glucose & $\mathrm{n} / \mathrm{a}$ & $\mathrm{n} / \mathrm{a}$ & $\downarrow$ & $\downarrow$ & - \\
\hline Hepatic index & $\mathrm{n} / \mathrm{a}$ & $\mathrm{n} / \mathrm{a}$ & $\uparrow$ & - & - \\
\hline Fecal TC & $\mathrm{n} / \mathrm{a}$ & $\mathrm{n} / \mathrm{a}$ & - & - & - \\
\hline Fat index & $\mathrm{n} / \mathrm{a}$ & $\mathrm{n} / \mathrm{a}$ & $\downarrow$ & - & - \\
\hline Kidney index & $\mathrm{n} / \mathrm{a}$ & $\mathrm{n} / \mathrm{a}$ & $\uparrow$ & - & - \\
\hline Testis index & $\mathrm{n} / \mathrm{a}$ & $\mathrm{n} / \mathrm{a}$ & $\uparrow$ & - & - \\
\hline Body weight gain & $\mathrm{n} / \mathrm{a}$ & $\mathrm{n} / \mathrm{a}$ & $\downarrow$ & $\uparrow$ & $\uparrow$ \\
\hline \multicolumn{6}{|l|}{ HCBD-fed mice } \\
\hline Serum TC & $\uparrow$ & $\downarrow$ & $\downarrow$ & - & $\uparrow$ \\
\hline Serum TG & $\downarrow$ & - & - & - & - \\
\hline Serum HDL & - & $\downarrow$ & - & - & $\uparrow$ \\
\hline Serum LDL & $\uparrow$ & $\downarrow$ & $\downarrow$ & - & - \\
\hline Serum LDL/HDL & $\uparrow$ & $\downarrow$ & - & $\downarrow$ & - \\
\hline Serum ALT & $\uparrow$ & $\uparrow$ & $\uparrow$ & $\downarrow$ & $\downarrow$ \\
\hline Hepatic TC & $\uparrow$ & $\downarrow$ & $\downarrow$ & $\downarrow$ & $\downarrow$ \\
\hline Hepatic TG & $\uparrow$ & $\downarrow$ & $\downarrow$ & $\downarrow$ & $\downarrow$ \\
\hline Hepatic glucose & $\downarrow$ & $\downarrow$ & $\downarrow$ & $\downarrow$ & $\uparrow$ \\
\hline Hepatic index & $\uparrow$ & $\uparrow$ & $\uparrow$ & - & - \\
\hline Fecal TC & $\uparrow$ & - & $\uparrow$ & - & - \\
\hline Fat index & $\downarrow$ & $\downarrow$ & $\downarrow$ & - & - \\
\hline Kidney index & - & - & $\uparrow$ & $\uparrow$ & - \\
\hline Testis index & - & - & $\uparrow$ & - & - \\
\hline Body weight gain & - & - & $\downarrow$ & $\uparrow$ & - \\
\hline
\end{tabular}

Notes: $\uparrow$, elevated or increased; $\downarrow$, inhibited or decreased; -, unaltered.

Abbreviations: ND, normal diet; HCBD, high cholesterol/bile salt (0.5\%/0.15\%, w/w) diet; FF, fenofibrate; AqSF-P, aqueous extract of Schisandrae Fructus pulp; BY, bicyclol; TC, total cholesterol; TG, triglyceride; HDL, high-density lipoprotein; LDL, low-density lipoprotein; ALT, alanine aminotransferase; vs, versus; n/a, not applicable. 
lipid accumulation in the liver and protect against FF-induced hepatotoxicity. Combination therapy with FF and AqSF-P (ie, drug and herb) may represent a good strategy for the management of fatty liver disease or other fat/lipid-related disorders, such as coronary heart disease, which is prevalent all over the world. ${ }^{53}$

\section{Acknowledgment}

This work was supported by a grant from the National Natural Science Foundation of China (grant 31071989).

\section{Disclosure}

The authors report no conflicts of interest in this work.

\section{References}

1. Li W, Wang D, Song G, Zuo C, Qiao X, Qin S. The effect of combination therapy of allicin and fenofibrate on high fat diet-induced vascular endothelium dysfunction and liver damage in rats. Lipids Health Dis. 2010;9:131.

2. Parikh NH, Parikh PK, Kothari C. Indigenous plant medicines for health care: treatment of diabetes mellitus and hyperlipidemia. Chin J Nat Med. 2014;12(5):335-344.

3. Bauer UE, Briss PA, Goodman RA, Bowman BA. Prevention of chronic disease in the 21st century: elimination of the leading preventable causes of premature death and disability in the USA. Lancet. 2014; 384(9937):45-52.

4. Pan SY, Gao SH, Zhou SF, Tang MK, Yu ZL, Ko KM. New perspectives on complementary and alternative medicine: an overview and alternative therapy. Altern Ther Health Med. 2012;18(4):20-36.

5. Keating GM, Croom KF. Fenofibrate: a review of its use in primary dyslipidaemia, the metabolic syndrome and type 2 diabetes mellitus. Drugs. 2007;67(1):121-153.

6. Ikewaki K, Tohyama J, Nakata Y, Wakikawa T, Kido T, Mochizuki S. Fenofibrate effectively reduces remnants, and small dense LDL, and increases HDL particle number in hypertriglyceridemic men - a nuclear magnetic resonance study. J Atheroscler Thromb. 2004;11(5):278-285.

7. Ohta T, Masutomi N, Tsutsui N, et al. Untargeted metabolomics profiling as an evaluative tool of fenofibrate-induced toxicology in Fischer 344 male rats. Toxicol Pathol. 2009;37(4):521-535.

8. Hajdu D, Aiglová K, Vinklerová I, Urbánek K. Acute cholestatic hepatitis induced by fenofibrate. J Clin Pharm Ther. 2009;34(5):599-602.

9. Dohmen K, Wen CY, Nagaoka S, et al. Fenofibrate-induced liver injury. World J Gastroenterol. 2005;11(48):7702-7703.

10. Panossian A, Wikman G. Pharmacology of Schisandra chinensis Bail.: an overview of Russian research and uses in medicine. J Ethnopharmacol. 2008;118(2):183-212.

11. Xiong J, Guo Y, Li LY, et al. A herbal composition of semen hoveniae, radix puerariae, and Fructus Schisandrae shows potent protective effects on acute alcoholic intoxication in rodent models. Evid Based Complement Alternat Med. 2012;2012:638197.

12. Xie W, Du L. Diabetes is an inflammatory disease: evidence from traditional Chinese medicines. Diabetes Obes Metab. 2011;13(4): 289-301.

13. Jeong SI, Kim SJ, Kwon TH, Yu KY, Kim SY. Schizandrin prevents damage of murine mesangial cells via blocking NADPH oxidase-induced ROS signaling in high glucose. Food Chem Toxicol. 2012;50(3-4):1045-1053.

14. Kwon DY, Kim da S, Yang HJ, Park S. The lignan-rich fractions of Fructus Schisandrae improve insulin sensitivity via the PPAR- $\gamma$ pathways in in vitro and in vivo studies. J Ethnopharmacol. 2011;135(2): 455-462.
15. Pan SY, Yu Q, Zhang Y, et al. Dietary Fructus Schisandrae extracts and fenofibrate regulate the serum/hepatic lipid-profile in normal and hypercholesterolemic mice, with attention to hepatotoxicity. Lipids Health Dis. 2012;11:120.

16. Sun N, Pan SY, Zhang Y, et al. Dietary pulp from Fructus Schisandra chinensis supplementation reduces serum/hepatic lipid and hepatic glucose levels in mice fed a normal or high cholesterol/bile salt diet. Lipids Health Dis. 2014;13:46.

17. Wang XY, Yu ZL, Pan SY, et al. Supplementation with the extracts of Schisandrae Fructus pulp, seed, or their combination influences the metabolism of lipids and glucose in mice fed with normal and hypercholesterolemic diet. Evid Based Complement Alternat Med. 2014;2014:472638.

18. Pan SY, Dong H, Zhao XY, et al. Schisandrin B from Schisandra chinensis reduces hepatic lipid contents in hypercholesterolaemic mice. J Pharm Pharmacol. 2008;60(3):399-403.

19. Pan SY, Yang R, Dong H, Yu ZL, Ko KM. Bifendate treatment attenuates hepatic steatosis in cholesterol/bile salt- and high-fat diet-induced hypercholesterolemia in mice. Eur J Pharmacol. 2006;552(1-3):170-175.

20. Pan SY, Dong H, Yu ZL, et al. Bicyclol, a synthetic dibenzocyclooctadiene derivative, decreases hepatic lipids but increases serum triglyceride level in normal and hypercholesterolaemic mice. J Pharm Pharmacol. 2007;59(12):1657-1662.

21. $\mathrm{Hu} \mathrm{W}, \mathrm{LI} \mathrm{Y}$, Zhang CZ. Enantioseparation of racemic antihepatitis new drug bicyclol with crystallization. Chin Chem Lett. 2005;16(11):1471-1473.

22. Li X, Zhou J, Chen S, et al. Role of bicyclol in preventing chemotherapeutic agent-induced liver injury in patients over 60 years of age with cancer. J Int Med Res. 2014;42(4):906-991.

23. Liu GT. Bicyclol: a novel drug for treating chronic viral hepatitis B and C. Med Chem. 2009;5(1):29-43.

24. Kumar DS, Prashanthi G, Avasarala H, Banji D. Antihypercholesterolemic effect of Macrotyloma uniflorum (Lam.) Verdc (Fabaceae) extract on high-fat diet-induced hypercholesterolemia in SpragueDawley rats. J Diet Suppl. 2013;10(2):116-128.

25. Lin ZJ, Zhang B, Liu XQ, Yang HL. Abdominal fat accumulation with hyperuricemia and hypercholesterolemia quail model induced by high fat diet. Chin Med Sci J. 2009;24(3):191-194.

26. Sharrett AR, Ballantyne CM, Coady SA, et al; Atherosclerosis Risk in Communities Study Group. Coronary heart disease prediction from lipoprotein cholesterol levels, triglycerides, lipoprotein (a), apolipoproteins A-I and B, and HDL density subfraction: the atherosclerosis risk in communities (ARIC) study. Circulation. 2001;104(10):1108-1113.

27. Barter P, Gotto AM, LaRosa JC, et al; Treating to New Targets Investigators. HDL cholesterol, very low levels of LDL cholesterol, and cardiovascular events. N Engl J Med. 2007;357(13):1301-1310.

28. Hsia SH, Pan D, Berookim P, Lee ML. A population-based, crosssectional comparison of lipid-related indexes for symptoms of atherosclerotic disease. Am J Cardiol. 2006;98(8):1047-1052.

29. Anderson TJ, Grégoire J, Hegele RA, et al. 2012 update of the Canadian cardiovascular society guidelines for the diagnosis and treatment of dyslipidemia for the prevention of cardiovascular disease in the adult. Can J Cardiol. 2013;29(2):151-167.

30. Deng B, Ou SQ, Zheng ZF. The relationship of LDL-c/HDL-c ratio with coronary artery disease degree and acute coronary syndromes. Chin J Hypertension. 2005;13(9):541-544.

31. Baligadoo S. Elevated coronary mortality in Mauritius: risk factors and genetic analyses. Bull Acad Natl Med. 2012;196(7):1381-1394.

32. Schofield JD, Liu Y, France MW, Sandle L, Soran H. A review of paradoxical HDL-C responses to fenofibrate, illustrated by a case report. J Clin Lipidol. 2014;8(4):455-459.

33. Linz PE, Lovato LC, Byington RP, et al. Paradoxical reduction in HDL-C with fenofibrate and thiazolidinedione therapy in type 2 diabetes: the ACCORD Lipid Trial. Diabetes Care. 2014;37(3):686-693.

34. Lella M, Indira K. A comparative study of efficacy of atorvastatin alone and its combination with fenofibrate on lipid profile in type 2 diabetes mellitus patients with hyperlipidemia. J Adv Pharm Technol Res. 2013;4(3):166-170. 
35. Niesor EJ, Gauthamadasa K, Silva RA, et al. Xanthophylls, phytosterols and pre- $\beta 1$-HDL are differentially affected by fenofibrate and niacinHDL-raising in a cross-over study. Lipids. 2013;48(12): 1185-1196.

36. Enomoto M, Adachi H, Hirai Y, et al. LDL-C/HDL-C ratio predicts carotid intima-media thickness progression better than HDL-C or LDL-C alone. J Lipids. 2011;2011:549137.

37. Trapani L, Segatto M, Pallottini V. Regulation and deregulation of cholesterol homeostasis: the liver as a metabolic "power station". World J Hepatol. 2012;4(6):184-190.

38. Chu JH, Wang H, Ye Y, et al. Inhibitory effect of schisandrin B on free fatty acid-induced steatosis in L-02 cells. World J Gastroenterol. 2011;17(19):2379-2388.

39. Espenshade PJ, Hughes AL. Regulation of sterol synthesis in eukaryotes. Annu Rev Genet. 2007;41:401-427.

40. Xu X, So JS, Park JG, Lee AH. Transcriptional control of hepatic lipid metabolism by SREBP and ChREBP. Semin Liver Dis. 2013;33(4): 301-311.

41. Gruben N, Shiri-Sverdlov R, Koonen DP, Hofker MH. Nonalcoholic fatty liver disease: a main driver of insulin resistance or a dangerous liaison? Biochim Biophys Acta. 2014;1842(11):2329-2343.

42. Kelly CT, Mansoor J, Dohm GL, Chapman WH 3rd, Pender JR 4th, Pories WJ. Hyperinsulinemic syndrome: the metabolic syndrome is broader than you think. Surgery. 2014;156(2):405-411.

43. Smith BW, Adams LA. Non-alcoholic fatty liver disease. Crit Rev Clin Lab Sci. 2011;48(3):97-113.

44. Jeong S, Yoon M. Fenofibrate inhibits adipocyte hypertrophy and insulin resistance by activating adipose PPAR alpha in high fat diet-induced obese mice. Exp Mol Med. 2009;41(6):397-405.

45. Kostapanos MS, Kei A, Elisaf MS. Current role of fenofibrate in the prevention and management of non-alcoholic fatty liver disease. World J Hepatol. 2013;5(9):470-478.
46. Kwon DY, da Kim S, Yang HJ, Park S. The lignan-rich fractions of Fructus Schisandrae improve insulin sensitivity via the PPAR- $\gamma$ pathways in in vitro and in vivo studies. J Ethnopharmacol. 2011;135(2): 455-462.

47. Joseph B, Kapoor S, Schilsky ML, Gupta S. Bile salt-induced prooxidant liver damage promotes transplanted cell proliferation for correcting Wilson disease in the long-evans cinnamon rat model. Hepatology. 2009;49(5):1616-1624.

48. Canet MJ, Cherrington NJ. Drug disposition alterations in liver disease: extrahepatic effects in cholestasis and nonalcoholic steatohepatitis. Expert Opin Drug Metab Toxicol. 2014;10(9):1209-1219.

49. Kobayashi A, Suzuki Y, Kuno H, Sugai S, Sakakibara H, Shimoi K. Effects of fenofibrate on plasma and hepatic transaminase activities and hepatic transaminase gene expression in rats. J Toxicol Sci. 2009;34(4):377-387.

50. Guo LY, Hung TM, Bae KH, et al. Anti-inflammatory effects of schisandrin isolated from the fruit of Schisandra chinensis Baill. Eur J Pharmacol. 2008;591(1-3):293-299.

51. Lou XE, Xu N, Yao HP, Chen Z. Bicyclol attenuates pro-inflammatory cytokine and chemokine productions in CpG-DNA-stimulated L02hepatocytes by inhibiting p65-NF-kappaB and p38-MAPK activation. Pharmazie. 2010;65(3):206-212.

52. Zhang Y, Pan SY, Zhou SF, et al. Time- and dose-toxicity relationships of schisandrin B- and Schisandrae Fructus oil-induced hepatotoxicity associated with triglyceride elevation in serum and liver in mice. Drug Des Devel Ther. 2014;8:1429-1439.

53. Kones R. Primary prevention of coronary heart disease: integration of new data, evolving views, revised goals, and role of rosuvastatin in management. A comprehensive survey. Drug Des Devel Ther. 2011 5:325-380.
Drug Design, Development and Therapy

\section{Publish your work in this journal}

Drug Design, Development and Therapy is an international, peerreviewed open-access journal that spans the spectrum of drug design and development through to clinical applications. Clinical outcomes, patient safety, and programs for the development and effective, safe, and sustained use of medicines are a feature of the journal, which

\section{Dovepress}

has also been accepted for indexing on PubMed Central. The manuscript management system is completely online and includes a very quick and fair peer-review system, which is all easy to use. Visit http://www.dovepress.com/testimonials.php to read real quotes from published authors. 